\title{
LA HUMANIDAD COMO CRITERIO NORMATIVO EN LA OBRA DE JUDITH BUTLER
}

\author{
Gabriel Bello Reguera, Anisa Azaovagh de la Rosa \\ Universidad de La Laguna \\ bttp://dx.doi.org/10.15304/ag.39.1.5479
}

\section{Resumen}

Este artículo aborda la contextualización de la ética de Butler en un marco teórico que da por supuesta la perspectiva deconstructiva y que, por su parte, es reconstruido de acuerdo a dos criterios, las nociones de "matriz disciplinal" y de "paradigma". Mediante ellas se trata de proporcionar un sistema de conceptos o categorías usuales en la teoría ética en general, pero redefinidas en términos butlerianos. Estas categorías a las que nos referimos son la acción, los sujetos, los juicios y los criterios morales y, que, aplicadas a la ética de Butler, dan lugar a una ética precaria en la que la humanidad normativa se revela como imposible universalmente y, por tanto, no puede ser utilizada como "fundamento" de un juicio moral universal. Por ejemplo, la que se sugiere mediante las manifestaciones de duelo por la humanidad de "los nuestros", víctimas de la violencia, de las que queda excluida estructuralmente la humanidad de "los otros".

Palabras clave: matriz disciplinal, paradigma, deconstrucción, humanidad, precariedad, ética.

\begin{abstract}
This paper approaches the contextualization of Butler's ethics in a theoretical framework that assumes the deconstructive perspective. It is reconstructed according to two criteria: the notions of "disciplinary matrix" and "paradigm". Through them, it is a question of establishing a system of concepts or categories usual in ethical theory, in general, but redefined in butlerian terms. These categories to which I refer are action, subjects, judgements, and moral criteria. If we apply them to Butler's ethic, it leads to a precarious ethic in which normative
\end{abstract}

Recibido: 16/12/2018. Aceptado: 24/01/2019. 
humanity would be impossible and, therefore, it cannot be used as a ground of a universal moral judgement. For instance, the precarious ethic suggested throughout the mourning for our people, victims of violence, from which is structurally excluded the humanity of the Others.

Keywords: disciplinary matrix, paradigm, deconstruction, humanity, precarity, ethics.

\section{El paradigma ético de Judith Butler}

Cabe resituar o resignificar la ética de la no violencia de J. Butler como una ética precaria. Y para ello recurriremos a dos nociones que proceden de la historia de la ciencia pero que pueden aplicarse, por analogía, a la ética: las de "matriz disciplinal" y "paradigma". ${ }^{1}$ La primera se refiere al conjunto articulado de conceptos que integran una teoría, la ética en este caso, como una disciplina identificable y reconocible a través del tiempo, y diferenciada de otras como el derecho, la política, la psicología o la biología, por citar las más próximas. Y la segunda al perfil conceptual o discursivo que la matriz teórica o conceptual adopta en contextos o marcos históricos y culturales diferentes; en el caso de la ética este perfil puede ser metafísico, teológico, biologista, psicologista o lingüístico.

Este último sería el paradigma de la ética de Butler y conviene perfilar algunos de sus rasgos básicos antes de entrar en su matriz teórica o disciplinal. Según una inteligente interpretación de Darwin es tarea de la especie humana, en su desarrollo bioevolutivo, la construcción de una moralidad que remedie la carencia de pautas instintivas de conducta, que la diferencia nuestra de otras especies animales. Darwin habría dejado el mensaje de que la ética no está predeterminada por la naturaleza y su devenir evolutivo como ha pretendido el naturalismo ético y pretende hoy cierta neuroética²-, sino que es un efecto de la actividad humana, cultural y, por tanto, lingüística. Después de haber explorado todo lo que compartimos con los demás animales, como cierta sensibilidad emocional, Darwin dirá que "lo único que realmente nos diferencia del resto de los seres vivos es la capacidad para

${ }^{1}$ Sobre los conceptos de "paradigma" y de "matriz disciplinal" aplicados a la ética, Bello Reguera, G., "¿Ética filosófica o ciencia del bien y del mal? La matriz Aranguren y otras claves de la ética española” en Claves de la razón práctica, no 197(2009) pp. 4-15. Esta aplicación procede de la analogía entre la historia de la ciencia, a la que los aplicó originariamente Kuhn, T.S., a la historia de la ética a la que los aplica Bello, G.

${ }^{2}$ Véase G. Bello, "El riesgo moral. Los límites de la vida humana y la democratización de la ética”, en Revista Iberoamericana de ciencia, tecnología y sociedad, vol. 7, n²0 (2012), pp. 129-143. 
la moral”. La naturaleza no es moral como el Jardín del Edén, sino “completamente amoral y ciega, despiadada y cruel, donde las criaturas están condenadas a vivir vidas de sufrimiento." 3

$\mathrm{Si}$, como sugiere Darwin, la moral no está dada por la naturaleza o en la naturaleza, sino que la humanidad debe "dársela" a sí misma, sólo puede ser realizada o performada como una tarea cultural y, por lo tanto, social, lingüística y política. El lenguaje es, aquí, intercambio comunicativo de signos, lingüísticos y no lingüísticos (icónicos: imágenes) y siempre está intervenido por el poder político (o económico) y sus extensiones mediáticas. La ética -igual que la política- queda asimilada al lenguaje performativo y desprendida del lenguaje naturalista o biologista y, desde luego, del lenguaje sobrenaturalista, teológico o metafísico. Este desprendimiento está en el núcleo de la metaética deconstrutiva en cuyo marco la ética resulta teóricamente precaria.

Esta visión de la ética se conecta directamente con la posición mayoritaria que adopta la filosofía moral contemporánea más o menos identificada con el giro lingüístico ${ }^{4}$ en cuyo marco se sitúa por derecho propio la obra de Butler. En su larga introducción a su libro Excitable Speech. A Politics of the Performative ${ }^{5}$, Butler introduce la noción de vulnerabilidad lingüistica cuya explicación remite a la constitución lingüística del sujeto, situadas, ambas, en el marco de la performatividad igualmente lingüística y todas ellas vinculadas a la política, tal como sugieren títulos como el mencionado o también Dispossession. The Performative in the Political. Sostiene que "atribuimos una agencia al lenguaje, un poder de herir, y nos presentamos como los objetos de esa trayectoria hiriente". También afirma que podemos actuar lingüísticamente para defendernos del lenguaje hiriente y su violencia, de modo que "ejercemos la fuerza del lenguaje incluso cuando intentamos contrarrestar su fuerza, atrapados en un enredo que ningún acto de censura puede deshacer." ${ }^{\prime}$ Esta fuerza lingüística que puede herir al sujeto en su identidad y, a la vez, le permite defenderse de la herida y de la vio-

${ }^{3}$ Tafalla, M., "Darwin, Melville y el lugar del ser humano en la naturaleza", Herrera Guevara A. (ed.), De animales y hombres. Studia Philosóphica, Madrid, Nueva/Ediciones de la Universidad de Oviedo, 2007, p. 138.

${ }^{4}$ Rorty, R., El giro lingüístico, Barcelona, Paidós, 1990. Para una visión un poco más amplia puede verse la Introducción de Bello Reguera, G., "Richard Rorty en la encrucijada de la filosofía postanalítica: entre pragmatismo y hermenéutica", del mismo autor, "Pragmática, hermenéutica y ética de la alteridad”, Oñate T. y otros (eds.), Crítica y crisis de Occidente. Al encuentro de las interpretaciones, Madrid, Dykinson, S.J., 2013.

${ }^{5}$ Butler, J., Lenguaje, poder e identidad, Madrid, Síntesis, 2004.

${ }^{6}$ Ibíd, p. 16. 
lencia verbal, es la performatividad en sus dos dimensiones, una formadora o formativa, constructiva o edificante de identidades, identificaciones y desidentificaciones, valores y normas, y otra deformadora o destructiva de ambos como en los casos del insulto o la descalificación que caracterizan el lenguaje del odio. Ello hace de la performatividad una categoría decisiva a la hora de dar cuenta de la significación política y ética. ${ }^{7} \mathrm{Al}$ mismo tiempo, es una categoría precaria, que expresa y materializa la precariedad humana. Porque la performatividad opera más allá de las categorías de verdad y falsedad y los sistemas de verificación y falsación. Los criterios a los que se atiene son, en la versión austiniana, la eficacia performativa (realizativa o comunicativa) en el marco de un sistema de normas dado y vigente, y en otras versiones como la derridiana o butleriana, la producción de diferencia mediante la subversión de la normalidad. ${ }^{8}$

\section{La ética y su matriz disciplinal: acción, sujeto y juicio}

Una vez identificado el paradigma teórico o conceptual en el que se enmarca la ética de Butler, estamos en mejores condiciones para aproximarnos a su matriz teórica o conceptual, a la que tampoco se ha referido de forma abierta y explícita. No es diferente de la que opera en otras teorías o paradigmas éticos a lo largo de la historia de la disciplina, en los que tampoco se encuentran referencias directas a la matriz en cuestión y a los conceptos que la integran, ya que se trata de una categoría reciente. Como en ellos, sin embargo, esta matriz está implícita y activa desde el mismo momento en que Butler pone en movimiento su discurso ético, a propósito de los atentados terroristas del 11 de septiembre de 2001 y la guerra "antiterrorista" subsiguiente. Nos referimos al Prefacio de Vida Precaria y al primero de los ensayos, "Explicación y absolución, o lo que podemos escuchar". En ambos, Butler, comienza a incluir en su léxico conceptos o categorías éticas que se irán abriendo a la ética de la no violencia en el ensayo final que da título al volumen. Los conceptos y categorías en cuestión - anticipados en la Introducción- son los siguientes: la acción, el sujeto, el juicio y los criterios:

\footnotetext{
${ }^{7}$ Ver, al respecto, Pérez Navarro, P., Del texto al sexo. Judith Butler y la performatividad, Madrid, Egales, 2008, y también E. Burgos, Qué cuenta como una vida. La pregunta por la libertad en Judith Butler, Madrid, Mínimo tránsito, 2008, cap. IV.

${ }^{8}$ Butler, J., El género en disputa. El feminismo y la subversión de la identidad, Barcelona, Paidós, 2007, pp. 173 y 253.
} 
$1^{\circ}$.- La acción moral. Nos referimos a los actos, acciones, prácticas y conductas violentas, de tipo militar y paramilitar, político y mediático, acompañados de, por un lado, las consecuencias o efectos que producen, como pérdidas de vidas, dolor, duelo, y agresividad reactiva y, por el otro, de las motivaciones, intenciones y justificaciones de unos y de otros. Sobre todo, desde el lado estadounidense. Este es el núcleo desencadenante de la situación global en juego. Convendría señalar, sobre la marcha, algunas cosas que aparecerán en otros contextos: que los actos o acciones referidos son, en realidad, interacciones; que pueden ser no lingüísticas y lingüísticas, entre las que operan relaciones complejas. El hecho de que se trate de inter-acciones pone de manifiesto dos estructuras básicas. En primer lugar, su condición inter-dependiente, que presupone dependencia entre ellas e insuficiencia por parte de cada una, dos de los rasgos que definen la precariedad. En segundo lugar, que se trata de una actividad exterior, social y política, diferenciada de la interior o interna, psicológica o mental. Entre ambas existen relaciones complejas ya que una no podría operar sin la otra, pero Butler concede prioridad a la primera a lo largo de toda su obra. Considera que la vulnerabilidad y la agresión constituyen el punto de partida de la vida política. ${ }^{9} \mathrm{Al}$ mismo tiempo, sitúa el punto de partida de su ética en la no agresión al otro vulnerable y su sustitución por la responsabilidad para con él. ${ }^{10} \mathrm{~A}$ partir de aquí, hace suya la categoría de alteridad entendida en su significación de "relación con el otro", "posición de otredad" o "condición de otro", en la que sitúa la ética en su doble dimensión de conducta práctica efectiva y de reflexión teórica o filosófica sobre ella.

$2^{\circ}$.- El sujeto moral. Se trata, ahora, de los sujetos implicados de un modo u otro en los actos, prácticas y conductas anteriores, así como en las valoraciones subsiguientes, en forma de juicios morales positivos o negativos. Son sujetos agentes o perpetradores de la violencia, musulmanes y estadounidenses, sujetos pacientes o víctimas en un lado y otro (con énfasis en el estadounidense), la mayor parte civiles e inocentes; y de sujetos que observan todo eso, como testigos y jueces morales, a partir de los medios de comunicación. Por ejemplo, la propia Judith Butler que se implica activamente en la problemática a través de su escritura. Todos estos "sujetos" están implicados en la misma actividad social, política y ética, hasta el punto de formar parte de ella. Como tales, no son autónomos, ni autosuficientes,

${ }^{9}$ Butler, J., Vida precaria. El poder del duelo y la violencia, Buenos Aires, Paidós, 2006, p. 13.

${ }^{10}$ Ibíd., pp. 15, 166 y ss. y Dar cuenta de sí mismo. Violencia ética y responsabilidad, buenos Aires, Amorrortu, 2009, pp. 117 y ss. 
sino insuficientes, cada uno de ellos y, por lo tanto, dependientes unos de otros, lo que los convierte en interdependientes.

Estos rasgos constituyen su precariedad. Y no están presentes sólo a la hora de actuar o tomar parte en la actuación común, sino también en su constitución misma como sujetos: están sujetados a la trama socio-lingüística en la que, desde la que y sobre la que actúan en una especie de realimentación. Esta "trama" no sólo está constituida por normas e instituciones diversas, sino también por otros sujetos sujetados igualmente a ella, pero también entre sí, unos a otros. Esta sujeción mutua o inter-sujeción es la que constituye la intersubjetividad que permea la obra de Butler a través de categorías diversas que irán apareciendo a lo largo de esta investigación.

La tensión entre exterioridad intersubjetiva e interioridad intrasubjetiva atraviesa toda la obra de Butler, desde Sujetos de deseo (1987) hasta Dispossessions (2013), pasando por Lenguaje, poder e identidad (1997) y Dar cuenta de uno mismo (2005) bajo diversas apelaciones de las que los títulos citados son ilustraciones. Unas y otras tienen que ver con los procesos de "producción del sujeto" en el marco de tramas o estructuras interpelativas, normativas e institucionales diversas, en la estela de M. Foucault, ${ }^{11} \mathrm{o}$ con la "socialidad de la autopoiesis", expresión tan paradójica como ilustrativa. ${ }^{12}$ Butler enmarca la vieja subjetividad en la subjetivación postmoderna y a esta en la intersubjetividad que resulta y, a la vez, hace posible, la intercomunicación como interdependencia de subjetividades diversas. Estas, aisladas unas de otras al estilo antiguo y moderno, platónico, cartesiano y kantiano, resultan ser insuficientes en sí mismas y para sí mismas, por ejemplo, para significarse o darse significación, lo cual las convierte en dependientes de otras y, por lo tanto, en interdependientes en términos lingüísticos y comunicativos: significantes o significativos.

$3^{\circ}$.- El juicio moral. Como en los casos anteriores, se trata del plural, no del singular: los juicios morales que emiten e intercambian entre sí, los diversos sujetos mencionados en el punto anterior. En los que valoran, negativa o positivamente, según el caso, las conductas, comportamientos, prácticas y acciones respectivas que, en el caso que nos ocupa, son violentas; sus efectos o consecuencias dolorosas, su motivaciones y justificaciones; y también a los sujetos agentes, pacientes o víctimas, y a los observadores (que también se juzgan entre sí). Todo ello en forma de denuncias, acusa-

${ }^{11}$ Butler, J., Dar cuenta de sí mismo..., o.c., p. 21 y Lenguaje, poder e identidad..., o.c., pp. 52-63.

${ }^{12}$ Butler J. y Athanasiou, A., Dispossession. The Performative in the Political, Cambridge, Polity Press, 2013, p. 64. 
ciones e imputaciones, de excusas y justificaciones. Estos juicios surgen de todas partes: de los agentes y pacientes de un lado y otro, pero también de los observadores que se sitúan, mediáticamente, a un lado u otro. ${ }^{13}$ De todo lo cual Butler infiere que no es posible un juicio moral único y último sobre lo acontecido, a pesar de las pretensiones del gobierno estadounidense de que ese juicio es el suyo y de que cualquiera que pretenda uno alternativo y diferente es cómplice de los que agredieron a Estados Unidos. Por el contrario, ella defiende la posibilidad de juicios alternativos pese a que pueda implicar cierto relativismo moral. No para defender que cualquier juicio moral es tan válido como otro, sino para dar a entender que un juicio moral con pretensiones absolutistas siempre puede ser relativizado por el otro alternativo o diferente. ${ }^{14}$

Por tanto, el juicio moral no es autosuficiente en sí mismo y por sí mismo, sino que su significación es dependiente de, entre otras cosas, el contraste con otros juicios morales, lo cual implica que unos y otros son interdependientes entre ellos. Recordamos que estos tres rasgos -insuficiencia, dependencia e interdependencia - son los que vienen caracterizando a la precariedad desde el comienzo de su obra y, para explorarlos un poco más, conviene distinguir claramente tres tipos relativamente diferenciados si bien inevitablemente solapados: juicios de hecho, juicios de valor y juicios de validez.

Los juicios de hecho son los que se refieren a la existencia empírica o fáctica de los actos y comportamientos violentos ocurridos, que constituyen el punto de partida de las interpretaciones y valoraciones morales y políticas. Es un juicio de hecho - que resultó ser falso- la afirmación de la existencia de armas de destrucción masiva esgrimida por el gobierno estadounidense como "justificación" de la guerra contra Irak. Como lo son todos los referentes a los efectos destructivos de los actos terroristas como, por ejemplo, el impacto de los aviones sobre las torres gemelas y la muerte de miles de personas afectadas por su derrumbe. O las informaciones sobre la invasión estadounidense de Irak y la muerte de decenas de miles de inocentes, etc. $\mathrm{O}$ sobre la existencia de centros de internamiento de prisioneros como Guantánamo, al margen del derecho internacional. ${ }^{15}$ Los juicios de hecho no son autosuficientes en su facticidad, ya que la información que contienen y trasmiten siempre está interferida por sesgos emotivos o valorativos implícitos, de tipo ético y político, pero lo que cuenta es su componente descriptivo o cognitivo, fáctico o empírico.

\footnotetext{
${ }^{13}$ Butler, J., Vida precaria..., o.c., pp. 14-16.

${ }^{14}$ Ibíd., p. 15.

${ }^{15}$ Ibíd., pp. 18 y 79 y ss.
} 
Los juicios de valor son los propiamente éticos o morales y son los que explicitan o visibilizan los sesgos valorativos anteriores en forma de proposiciones del tipo "la seguridad nacional es buena" o "el terrorismo es malo", o bien sustituyendo bueno y malo por justo o injusto, correcto o incorrecto, etc. También puede haber juicios de valor implícitos en el uso de adjetivos emocionales como demoníaco, odioso, insoportable, inaceptable, inhumano, humanitario, inocente, violento, terrorista, contraterrorista, etc., tan usados y abusados, cuyo significado es netamente valorativo. Estos dos tipos de juicios - explícitos e implícitos- son los normales en un contexto cultural determinado, sea el occidental o el oriental, a los que nos referimos como juicios morales o éticos y que usamos a la hora de tomar posiciones éticas y políticas sobre comportamientos y personas de un lado u otro, como Sadam Husein y Bin Laden o Bush y lo perpetrado por cada uno de ellos. Es la situación típica que ha suscitado el multiculturalismo que ha situado en el centro del debate los juicios de valor situados en culturas diferentes. ${ }^{16}$

En este marco surgen los juicios de validez universal y obligatoria o, en su caso, de invalidez, sobre los juicios morales anteriores de uno y otro lado. O sobre su racionalidad o no racionalidad. Estos juicios, siendo metateóricos - ya que su objeto son los juicios de valor, de nivel teórico más bajo- tienen una significación práctica o pragmática, política y ética, decisiva por los dos tipos de efectos que podrían producir si fueran posibles. El primero es la certeza metaética en la justificación de los juicios éticos o morales propios - los "nuestros"-, así como en la deslegitimación y condena de los de "ellos". Desde esta certeza, en segundo lugar, se puede legitimar la violencia propia o "de los nuestros" y deslegitimar la de "los otros". Estos dos efectos, sin embargo, están contaminados por la confusión entre "lo nuestro" y "lo universal" o, dicho de otro modo, por la simulación del nosotros particular como si fuera la humanidad universal.

Este equívoco es el que pretende deconstruir Butler cuando rechaza "cualquier forma radical de autosuficiencia y soberanía irrestricta," 17 cuya expresión política presupone su articulación ética y metaética en expresiones como "eje del mal" y otras similares. Por eso recurre a la categoría de

${ }^{16}$ Ver Bello Reguera, G., El valor de los otros. Más allá de la violencia intercultural, Madrid, Biblioteca Nueva, 2006, sobre todo el ensayo "Política del valor intercultural"; y Emigración y ética. Humanizar y deshumanizar, Madrid, Plaza y Valdés, 2011, sobre todo los ensayos "Interculturalidad e identidades sobrevaloradas" y "Demonizar (a Occidente), deshumanizar (a Oriente) y otras inhumanizaciones”.

${ }^{17}$ Butler, J., Vida precaria..., o.c., p. 15. 
precariedad que cuestiona radicalmente — deconstruye- esa "autosuficiencia y soberanía”. Tarea que ya había iniciado en su primera época con la subversión deconstructiva de la identidad que, de un modo u otro, remite a la "autosuficiencia y soberanía irrestrictas" de la identidad patriarcal, que ahora, en su segunda época, atribuye a la identidad política estadounidense.

Son estas razones de fondo las que explican la pertinencia de una metaética deconstructiva, como la sugerida en este trabajo, que se puede encontrar implícita pero activa en autores como Derrida, Rorty o Butler. Y, si bien con un relieve menor, en Bernstein, no en vano comparte con todos ellos, desde su adhesión al pragmatismo clásico, el "falibilismo pragmático" así como una visión pragmática o comunicativa del lenguaje y, desde ella, un compromiso inequívoco con la política democrática y en contra de la autoritaria o totalitaria. ${ }^{18}$ Desde esta perspectiva se puede comprender que la tarea de la metaética deconstructiva no sólo es desmontar la confusión de la universalidad metaética con una particularidad ética determinada, sino también la noción misma de universalidad y, con ella, la posibilidad de una metaética universalista. ${ }^{19}$ Cualquiera podría esgrimirla a su favor y en contra de los otros.

\section{Los criterios}

La noción o categoría de “criterio" está asociada de algún modo a la de juicio y, por lo tanto, a los juicios mencionados en el punto anterior: sería aquello que los hace posibles. Sin embargo, la palabra "criterio" no es de uso muy frecuente en la reflexión teórica y metateórica sobre la ética y la metaética y quizá por eso su significado no está normalizado, ni siquiera en los diccionarios. En la RAE aparecen tres significados: "norma o pauta para conocer la verdad de una cosa", "capacidad o facultad para comprender” y "juicio u opinión sobre algo". La primera le imprime un matiz abiertamente cognitivo o epistemológico que deja fuera el ético y el político y las otras

${ }^{18}$ Ver Bello Reguera, G., "El giro filosófico rortyano: del autoritarismo a la democracia", en Sierra A., González y Martínez, F.J. (eds.), La filosofía ante el ocaso de la democracia representativa, Barcelona, Laertes, 2013 y Azaovagh de la Rosa, A., "La política de la violencia, el abuso del mal y la crítica a la guerra", en Oximora. Revista Internacional de Ética y Política, no 11, 2017, pp. 59-77.

${ }^{19} \mathrm{Al}$ respecto, Bello Reguera, G., "La relatividad de los derechos humanos. Más allá del etnocentrismo occidental”, en Rosales M.J. y Toscano Méndez, M. (eds.), Ética y ciudadanía democrática: Estudios en homenaje a José Rubio Carracedo, Universidad de Málaga, Contrastes, 2011. 
dos no lo corrigen. Un diccionario escolar define el criterio como "norma o principio de discernimiento para conocer, seleccionar o distinguir cosas" de las que, desde luego, no se excluye a las cosas éticas. Finalmente, si se busca "criterio ético" en Google aparecen dos acepciones complementarias: "elegir apropiadamente evitando daño a otros y favoreciendo a la sociedad" y "discernimiento entre lo correcto y lo incorrecto".

En estas definiciones se repiten algunos elementos como: la elección, el discernimiento y la distinción; las normas, pautas o principios que la hacen posible; valores abiertamente éticos como "no dañar a otros" y "favorecer a la sociedad"; la capacidad o facultad que permite poner en práctica todo lo anterior. Se puede concluir que la palabra "criterio" se refiere a aquello que permite elegir, discernir o distinguir entre opciones morales diferentes, pero hay que tener en cuenta dos tipos de elecciones o discernimientos. Una es la que tiene por objeto conductas diferentes - cometer un acto terrorista o no hacerlo, hacer la guerra o no hacerla-, en cuyo caso el criterio que los hace posibles son las normas y los valores vigentes en el contexto de que se trate. Otra es la que tiene por objeto elegir, discernir o distinguir entre los valores y las normas a seguir en situaciones como las anteriores en las que hay opciones diferentes. ¿Hay o debe haber algún tipo de metacriterio - metavalor o metanorma- que lo haga posible de forma inequívoca, que permita un discernimiento y una elección únicos, primeros o últimos, que sean infalibles y, por lo tanto, indiscutibles?

Para responder adecuadamente a esta pregunta, así como para ampliar y detallar un poco el marco de comprensión del criterio o los criterios morales, es útil diferenciarlos según la modalidad del juicio en el que operan haciéndolo posible. Entonces, encontraremos que los criterios no son todos iguales. Los hay propios de los juicios de hecho, que son cognitivos o epistemológicos; otros asociados a los juicios de valor que son los propiamente éticos o morales y, en tercer lugar, los vinculados a los juicios de validez universal que son los criterios metaéticos. Entre los primeros se cuentan la verdad y la objetividad empíricas y sus contrarios, el error y la falsedad, así como la coherencia y la racionalidad. Estos criterios impiden confundir la realidad con el deseo: por ejemplo, el de que hubiera habido armas de destrucción masiva en Irak; su existencia hubiera evitado al Gobierno estadounidense una mentira o falsedad global para justificar la guerra, pero resultó que no eran hechos empíricos o no existían realmente. Al contrario, las fotografías de personas torturadas tomadas en los centros de Abu Ghraib y Guantánamo son criterios fácticos decisivos a la hora de sostener la realidad material no sólo de esos centros, sino de las actividades mate- 
rializadas en ellos: son exhibiciones de la verdad y la objetividad empíricas de lo que afirman. ${ }^{20}$ Como puede apreciarse, juicios de hecho como los anteriores con su verdad empírica tienen una significación valorativa y ética decisivas, ya que de su verdad o falsedad depende que los juicios de valor ético y político tengan por objeto acciones y situaciones efectivamente reales como la tortura, o meramente ficticias o imaginarias, como la existencia de armas de destrucción masiva en Irak. En casos y contextos como estos, criterios cognitivos como la verdad y la objetividad operan como criterios morales y políticos de enorme significación.

Si nos situamos en los juicios de valor, entonces los criterios ya no son cognitivos como la verdad y la objetividad sino éticos como, por ejemplo, los ideales, los valores y las normas que están vigentes y operan de hecho en contextos sociales y culturales concretos, como la sinceridad o la veracidad (que son distintos de la verdad empírica). O como la democracia y los derechos humanos pese al mal uso o abuso que se hizo de ellos para justificar la guerra de Irak (cuando la existencia de armas de destrucción masiva se reveló una ficción política). Estos valores son los que, aparentemente, inspiran la ética y la política occidentales, junto con otros como la libertad, la dignidad, la igualdad y la justicia. Otro ejemplo es la Sharia, ley divina y humana, con la constelación de valores que la inspiran como la compasión, el amor, la paz, la belleza, la justicia. ${ }^{21}$ Obviamente, de un lado y otro entre los valores morales y políticos más decisivos están la defensa y la seguridad de la comunidad y la sociedad propias, de la integridad física e identitaria de sus miembros, así como de la cultura que la inspira. Estos valores son los que, llegado el caso, justifican la guerra.

Finalmente, están los criterios que podrían hacer posibles los juicios de validez universal (metaéticos). O imposibles. Debido, precisamente, a estas dos opciones los criterios correspondientes aparecen en una relación de tensión que los escinde en dos tipos: los que podrían hacerlos posibles y sus contrarios, los que los vuelven imposibles. Unos son constructivos o reconstructivos de una metaética racionalista, universalista, absolutista y fundamentalista y los otros negativos de esa metaética e inspiradores de otra: la deconstructiva.

Entre los primeros se cuenta la idea de validez universal que, por su parte, se apoya en otra, la supuesta presencia originaria, ontológica o metafísica que, como la Idea de Bien platónica, el imperativo categórico kantiano

${ }^{20}$ Butler, J., Marcos de guerra. Las vidas lloradas, Barcelona, Paidós, 2010, pp. 95-144.

${ }^{21}$ Nasr, S.H., El corazón del islam, Barcelona, Kairós, 2007. 
o la voluntad divina, ${ }^{22}$ opera como fundamento o premisa primera o última de un razonamiento moral concluyente y obligatorio para todo ser racional. Kant es, quizá, el exponente paradigmático de esta opción cuando sostiene que "la naturaleza humana existe como un fin en sí mismo" que opera como el "principio objetivo" de la voluntad racional o razón práctica. ${ }^{23} \mathrm{Un}$ rasgo definitorio de este fundamento racional de la ética es su universalidad que Kant incluye en su imperativo categórico. ${ }^{24}$

Tocamos aquí otro punto crítico ya que Butler considera (siguiendo a Adorno), que la universalidad representa la violencia ética contra la particularidad y la singularidad, a lo que dedica en parte el segundo de sus libros sobre ética, cuyo subtítulo es, significativamente, Violencia ética y responsabilidad. ${ }^{25}$ De modo similar, Rorty critica explícitamente la universalidad racional y lo hace, casualmente, por su proximidad al falogocentrismo patriarcal. De modo que en el "fundamento universal" kantiano parece confundirse la "presencia" de una naturaleza racional, supuestamente universal, con la de la voluntad patriarcal. Por supuesto, si Rorty usa el término "falocentrismo" quiere decir que asocia a Derrida, el autor del término, a la crítica de la universalidad.

Podemos ver, entonces, en la crítica de la universalidad y la validez universal, el objetivo de la metaética deconstructiva, lo cual plantea la pregunta de cuál es el criterio o los criterios de esta metaética. La respuesta está, a propósito de Derrida, Rorty y la propia Butler, condensado en tres elementos. El primero es la crítica de una presencia metafísica como origen o punto de partida y como referente último de la significación. El segundo es la inexistencia de un léxico último que refleje de forma inmediata y directa esa presencia, que lo convertiría en absolutamente verdadero. Y el tercero la visión pragmática, realizativa o performativa, del lenguaje que explica su significado por los efectos o realizaciones que produce en la práctica, antes

\footnotetext{
${ }^{22}$ Este criterio se encuentra tanto en Oriente como en Occidente sometido, cada uno, a su respectivo Dios al que sus creyentes consideran el "verdadero", a diferencia de cualesquiera otros que serían falsos. Sobre las pretensiones universalistas del catolicismo, Véase Küng, H., Proyecto de una ética mundial, Madrid, Trotta, 1990, pp. 75-76. Sobre la confrontación de pretensiones universalistas, seguidas de la descalificación del "otro", ver Buruma, I. y Margalit, A., Occidentalismo. Breve historia del sentimiento antioccidental, Barcelona, Península, 2005.

${ }^{23}$ Kant, I., Fundamentación para una metafísica de las costumbres, Madrid, Alianza, 2002, p. 115.

${ }^{24}$ Ibid., p. 104.

${ }^{25}$ La referencia a Adorno puede verse en Dar cuenta de sí mismo, o.c., p. 15.
} 
y más allá de su sometimiento al criterio de verdad y falsedad. Esta visión del lenguaje es prioritariamente política antes que epistemológica. ${ }^{26}$

\section{La humanidad como criterio ético y metaético}

La universalidad que la metaética deconstructiva deconstruye es, en realidad, propia de la humanidad o de la identidad humana. ¿Significa eso que la humanidad o identidad humana es, igualmente, alcanzada por la deconstrucción? Si lo fuera, ¿qué significación tendría o podría tener?

Para aproximarnos a una respuesta será útil comenzar distinguiendo dos significados del término "humanidad", uno descriptivo y otro axiológico y normativo. Podemos hablar de una humanidad descriptiva, realmente existente en la dimensión presente-pasado, tal como registran las ciencias naturales y sociales. Y también podemos hablar de una humanidad axiológica y normativa, tal como sería bueno o valioso que fuera en la dimensión presente-futuro según las diversas representaciones religiosas o filosóficas. ${ }^{27}$ Estas "dos humanidades" se solapan en los cuerpos, en su constitución biológica, cultural y lingüística, en la interacción o interactividad entre unos y otros y en los efectos a que dan lugar como, por ejemplo, la creación cultural de valores y normas o la construcción de representaciones de la humanidad misma (imágenes, visiones, ideas, etc.). La humanidad biológica de los cuerpos humanos no puede ser deconstruida en el sentido de la metaética deconstructiva, aunque sí puede ser destruida o mutilada mediante la violencia física. Pero la humanidad cultural y lingüística sí puede serlo, es decir, sus representaciones en tanto construcciones culturales y lingüísticas $y$, entre ellas, las que le confieren una significación valorativa o normativa, ética y política, por ejemplo, las que la presentan como valiosa, digna de respeto y reconocimiento; como feliz, justa, libre, altruista, compasiva, egoísta, racional, etc. O en términos opuestos: irracional, egoísta, agresiva, etc. Lo que puede ser deconstruido son las fundamentaciones de este tipo de representaciones, sus pretendidas conexiones con una supuesta divinidad, o una naturaleza humana (o una sustancia, o esencia o idea, etc.) que predeterminaría a los seres humanos a ser (identidad) y a actuar (agencia) de un modo "natural", único y último. Esta supuesta naturaleza humana no tiene

\footnotetext{
${ }^{26}$ Ver Bello Reguera, G., El giro filosófico rortyano: del autoritarismo a la democracia”, cit.

${ }^{27}$ Sobre estas dos dimensiones de la humanidad, descriptiva y normativa, Bello Reguera, G., "Superhumanizar(se) e infrahumanizar: la frontera antropológica", en Emigración y ética. Humanizar y deshumanizar, Plaza y Valdés, Madrid, 2011.
} 
un significado descriptivo sino axiológico o normativo y, como tal, creado o construido lingüísticamente. Por eso puede ser deconstruida. En este sentido, lo que puede ser deconstruido, así pues, son las representaciones de la humanidad y, en especial aquellas que tienen una significación práctica, ética y política de tipo autoritario o totalitario. Tales representaciones no son epistemológicas, como pretende la metafísica y la ontología clásicas (o la neurociencia postmoderna) ni, por lo tanto, verdaderas o falsas, sino políticas. Su significado no es la humanidad biológica que supuestamente describen, sino la humanidad valorativa y normativa que construyen como criterio de las prácticas éticas y políticas futuras. ${ }^{28}$

Estas reflexiones proporcionan una comprensión adecuada de manifestaciones de Butler como cuando concluye su ensayo Vida precaria afirmando que si las humanidades tienen algún futuro es como crítica cultural y si esta crítica tiene alguna tarea es la de "devolvernos a lo bumano allí donde no esperamos hallarlo, en su fragilidad y en el límite de su capacidad de tener algún sentido." ${ }^{29}$ Lo que nos está diciendo Butler es que lo humano está en su precariedad. No sólo en la precariedad de la vida como tal vida, abocada a la muerte, la enfermedad, etc., sino también en la precariedad de la representación de esa vida como humana en su apertura axiológica y normativa. Aquí la biología se queda corta y no disponemos de un referente análogo. Esta situación es la que lleva a Butler a afirmaciones audaces como la siguiente:

Lo humano se afirma indirectamente en esa disyuntiva que vuelve su representación imposible - una disyuntiva expresada por la imposibilidad de la representación-. Para que la representación exprese entonces lo humano no sólo debe fracasar, sino que debe mostrar su fracaso. Hay algo irrepresentable que sin embargo tratamos de representar, y esta paradoja debe quedar retenida en la representación que hacemos. ${ }^{30}$

Ello quiere decir que lo humano, la humanidad o la vida humana no son ni una realidad ni una representación que puedan operar como un criterio metaético fuerte o robusto, un metacriterio capaz de aportar una solución metaética a los problemas políticos globales. Sin embargo, lo humano, la humanidad o la vida humana está por todas partes de la obra de Butler como su referente básico. A este respecto es ilustrativo el título que pone Elvira Burgos a su importante estudio: Qué cuenta como una vida. La pregunta por la libertad en Judith Butler. Aunque en él no aparece en adjetivo

\footnotetext{
${ }^{28}$ Remitimos otra vez a Bello Reguera G., "El giro filosófico rortyanano: del autoritarismo a la democracia", ed. cit.

${ }^{29}$ Butler, J., Vida precaria..., o.c., p. 188. La cursiva es nuestra.

${ }^{30}$ Ibid., p. 180.
} 
"humana" está claro que la vida por la que interroga la autora no es ni vegetal, ni animal ni artificial. No es muy frecuente poner o situar a la vida humana, de forma abierta y explícita, como el objeto directo de la reflexión y el discurso filosóficos. Sin embargo, como sugiere el título mencionado, eso es lo que hace Judith Butler a lo largo de su obra: situar a la vida humana y, más específicamente, a lo humano de esa vida, la humanidad, como referente constante y permanente. Pero no bajo una representación absoluta, única y última. Por ejemplo, cuando ha de afrontar el problema de la violencia y sus efectos sobre la vida de las víctimas humanas: no sólo sobre su vida biológica o animal, en forma de muerte, heridas o mutilaciones corporales, sino también sobre la vida psicológica y moral de los sobrevivientes, en forma de dolor y duelo. Pero también en forma de una reacción o respuesta a los violentos, tan violenta o más que la suya, por la que han sido interpelados ellos y las vidas de sus seres queridos, miembros de la misma comunidad.

Esta respuesta consiste, en buena medida, en la negación de su pertenencia a la humanidad o a lo humano de la vida humana, lo cual se expresa o externaliza al menos de dos formas. Una como negación del duelo con el que lloran las vidas queridas o apreciadas, valoradas, lo cual es una forma de negarles valor o dignidad humana y, por lo tanto, excluirlos de la humanidad o de lo humano: por eso deben ser eliminados de cualquier modo, incluida la violencia. Y la otra en forma de tortura, una práctica llevada a cabo por los estadounidenses en Abu Ghraib y Guantánamo, a la que H. Arendt y posteriormente Rorty habían caracterizado como una forma de deshumanización. ${ }^{31}$ Aquí tocamos otro punto crítico decisivo que se puede enunciar en algunas preguntas: ¿qué es lo que se elimina en la deshumanización de un ser humano?, ¿qué es lo que humaniza a un ser humano?, ¿en qué consiste la identidad humana o humanidad?, ¿qué humanidad utilizan los estadounidenses como norma, qué humanidad normativa, para deshumanizar a los terroristas y los de su entorno: la suya propia y particular o una representación universal? ¿Es posible una representación de la humanidad que trasforme la respuesta violenta a los violentos en otra no violenta?

${ }^{31}$ Un tratamiento conjunto de la deshumanización en Arendt y Rorty puede verse en Bello Reguera, G., "Diferencia negativa, alteridad e interhumanidad”, ed. cit. 


\section{Conclusiones}

La consecuencia de la condición autorreflexiva de la precariedad afecta o contagia a la ética de la violencia de Butler, así como a su deriva metaética. Esta es la razón del énfasis que este artículo pone, por un lado, en la metaética deconstructiva y, por el otro, en lo que se denomina paradigma lingüístico de la ética. La metaética deconstructiva desmonta la creencia o convicción filosófica de que existe o puede existir un juicio moral dotado de validez universal y, por lo tanto, universalmente obligatorio, con el que justificar la violencia contra el otro o los otros. Lo desmontado o deconstruido es la idea o categoría de validez universal que alguien (un yo o un nosotros) pudiera atribuir a sus propios juicios morales particulares, estrategia puesta en juego por el particularismo patriarcal. Por la misma razón tampoco se puede recurrir a un juicio moral universalmente válido y obligatorio para justificar una ética de la no violencia que, por esa razón, no podrá por menos de ser una ética precaria. Dado que la expresión "metaética deconstructiva" es infrecuente y que la propia Butler no la utiliza, aunque su contenido metódico está presente en su obra, hemos creído conveniente y necesario recurrir a autores que han abordado de frente la metodología filosófica deconstructiva.

Por su parte, el paradigma lingüístico en el que se sitúa la ética de Butler permite, entre otras cosas, dar razón de la metaética deconstructiva. La cuestión estriba en que ese paradigma asocia a la ética a los actos de habla $y$ de escritura implicados en su significación valorativa y normativa. Dichos actos, que también son comunicativos, son actos del cuerpo y no del alma, del espíritu o de una mente supuestamente separada del cuerpo; y el cuerpo es una entidad biolingüística situada en un tiempo histórico y en un espacio sociológico, no en un mundo ideal o suprahistórico. Por tanto, tampoco son actos estrictamente biológicos o naturales, sino biosociales.

Esta condición corporal, biolingüística, de la ética de Butler, es la que garantiza una metaética deconstructiva de las éticas metafísicas en cualquiera de sus versiones. Al mismo tiempo, es la que vuelve imposible la representación de una humanidad normativa universalmente, que pudiera ser utilizada como "fundamento" de un juicio moral universal. Por ejemplo, la que se sugiere mediante las manifestaciones de duelo por la humanidad de "los nuestros”, víctimas de la violencia, de las que queda excluida estructuralmente la humanidad de "los otros". La primera sería normativa, mientras que la segunda sería su negación. En una línea similar, la ausencia de una humanidad normativa no sólo afecta a quienes querrían usarla para justi- 
ficar su violencia, sino también a quienes se podrían sentir impulsados a usarla para justificar su no violencia. Si fuera así, pondrían en juego la misma violencia simbólica en nombre de la no violencia. Es por ello por lo que cualquier juicio a favor de la no violencia no deja de ser una proscripción o propuesta totalmente falible, nunca un fundamento moral último, universalmente obligatorio. La vulnerabilidad corporal introduce ya la violencia y la no violencia como procedentes de la dimensión social de nuestros cuerpos. Por ello, ambas - la violencia y la no violencia- constituyen una lucha en la que Butler hace consistir el dilema que define la práctica ética. Una pugna que se juega a través de las normas socialmente establecidas como consecuencia de la dimensión invariablemente sociolingüística del cuerpo.

\section{Bibliografía}

Azaovagh de la Rosa, A., "La política de la violencia, el abuso del mal y la crítica a la guerra", en Oximora. Revista Internacional de Ética y Política, n ${ }^{\circ}$ 11, 2017.

Bello Reguera, G., "Richard Rorty en la encrucijada de la filosofía postanalítica: entre pragmatismo hermenéutica”, en R. Rorty, El giro lingüístico, Barcelona, Paidós, 1990.

Bello Reguera, G., El valor de los otros. Más allá de la violencia intercultural, Madrid, Biblioteca Nueva, 2006.

Bello Reguera, G., "¿Ética filosófica o ciencia del bien y del mal? La matriz Aranguren y otras claves de la ética española”, Claves de la razón práctica, $\mathrm{n}^{\circ}$ 197(2009), pp. 4-15.

Bello Reguera, G., "La relatividad de los derechos humanos. Más allá del etnocentrismo occidental", en Rosales J.M. y Toscano Méndez, M. (eds.), Ética y ciudadanía democrática: Estudios en homenaje a José Rubio Carracedo, Universidad de Málaga, Contrastes, 2011.

Bello Reguera, G., Emigración y ética. Humanizar y deshumanizar, Plaza y Valdés, Madrid, 2011.

Bello Reguera, G., "El riesgo moral. Los límites de la vida humana y la democratización de la ética", en Revista Iberoamericana de ciencia, tecnología y sociedad, vol. 7, n²0 (2012), pp.129-143.

Bello Reguera, G., "Pragmática, hermenéutica y ética de la alteridad", Oñate T. y otros (eds.), Crítica y crisis de Occidente. Al encuentro de las interpretaciones, Madrid, Dykinson, S.J., 2013. 
Bello Reguera, G., "El giro filosófico rortyano: del autoritarismo a la democracia”, en Sierra González A. y Martínez, F.J. (eds.), La filosofía ante el ocaso de la democracia representativa, Barcelona, Laertes, 2013.

Burgos, E., Qué cuenta como una vida. La pregunta por la libertad en Judith Butler, Madrid, Mínimo tránsito, 2008.

Buruma, I. y Margalit, A., Occidentalismo. Breve historia del sentimiento antioccidental, Barcelona, Península, 2005.

Butler, J., Lenguaje, poder e identidad, Madrid, Síntesis, 2004.

Butler, J., Vida precaria. El poder del duelo y la violencia, Buenos Aires, Paidós, 2006.

Butler, J., El género en disputa. El feminismo y la subversión de la identidad, Barcelona, Paidós, 2007.

Butler, J., Dar cuenta de sí mismo. Violencia ética y responsabilidad, Amorrortu, Buenos Aires, 2009.

Butler, J., Marcos de guerra. Las vidas lloradas, Barcelona, Paidós, 2010.

Butler, J., y Athanasiou, A., Dispossession. The Performative in the Political, Cambridge, Polity Press, 2013.

Kant, I., Fundamentación para una metafísica de las costumbres, Madrid, Alianza, 2002.

Küng, H., Proyecto de una ética mundial, Madrid, Trotta, 1990.

Nasr, S.H., El corazón del islam, Barcelona, Kairós, 2007.

Pérez Navarro, P., Del texto al sexo. Judith Butler y la performatividad, Madrid, Egales, 2008.

Rorty, R., El giro lingüístico, Barcelona, Paidós, 1990.

Tafalla, M., "Darwin, Melville y el lugar del ser humano en la naturaleza", Herrera Guevara, A. (ed.), De animales y hombres. Studia Philosóphica, Madrid, Nueva/Ediciones de la Universidad de Oviedo, 2007. 